\title{
PARA ALÉM DAS EXPLICAÇÕES BIOLÓGICAS: REFLEXÕES FILOSÓFICAS ACERCA DA DEPRESSÃO E DO SOFRIMENTO DO SUJEITO DO DESEMPENHO
}

\author{
Artur Junior Santos Cardoso ${ }^{1}$ \\ Lucas Rocha Gonçalves ${ }^{2}$
}

Resumo: O presente artigo tem como pretensão oferecer um olhar outro acerca da depressão. Nossa análise sobre tal fenômeno encontra na filosofia, sobretudo, de Byung-Chul Han, uma possibilidade interessante de ir além das explicações psiquiátricas. Entretanto, são nelas que esse texto inicia sua discussão: a hipótese serotoninérgica da depressão é apresentada, mas também, problematizada, pois, muito embora a psiquiatria encontre nela ainda hoje a sua tese nuclear acerca do comportamento depressivo, é mostrado aqui que, além de ser uma teoria ausente de comprovação científica, também carece de consistência para explicar o avanço da depressão ao redor do mundo. É diante da impossibilidade de pensar a depressão biologicamente que, no segundo momento deste artigo, há um esforço para analisar os modos de estruturação social contemporâneos, baseados na positivação da sociedade e na busca desenfreada por desempenho, e buscar nos mesmos, fatores desencadeantes do comportamento depressivo. A última parte do texto se concentra em apresentar um panorama filosófico centrado nas perspectivas de Han acerca da depressão. Através da exposição do mito de Eros e Psique, o artigo encerra sua análise mostrando a influência que o desaparecimento do Outro e a pressão por desempenho exerce na formação de uma sociedade de pessoas depressivas.

Palavras-chave: Depressão; Positividade; Desempenho.

\begin{abstract}
This article is intended to offer another look at depression. Our analysis of this phenomenon finds in Byung-Chul Han's philosophy, above all, an interesting possibility to go beyond psychiatric explanations. However, it is in them that this text starts its discussion: the serotonergic hypothesis of depression is presented, but also problematized, because, although psychiatry still finds in it today its nuclear thesis about depressive behaviour, it is shown here that, besides being a theory absent of scientific proof, it also lacks consistency to explain the advance of depression around the world. It's facing the impossibility of thinking about depression biologically that, in the second moment of this article, there is an effort to analyze the contemporary modes of social structuring, based on society's positivation and the unrestrained search for performance, and to look for in them, triggering factors of depressive behavior. The last part of the text focuses on presenting a philosophical panorama focused on Han's perspectives on depression. Through the exposition of the myth of Eros and Psyche, the article closes its analysis showing the influence that the disappearance of the Other and the pressure for performance exerts in the formation of a society of depressive people.
\end{abstract}

Keywords: Depression; Positivity; Performance.

\footnotetext{
${ }^{1}$ Artur é psicólogo e membro/idealizador do Grupo de Estudos e Pesquisas em Byung-Chul Han (GEPEB). Realiza também pesquisas nas seguintes áreas: filosofia, linguagem, história, modernidade líquida, neoliberalismo, psicopatologia e mundo do trabalho. Currículo Lattes: http://lattes.cnpq.br/9131949057032157.

${ }^{2}$ Psicólogo, membro do Grupo de Pesquisas e Estudos em Byung-Chul Han (GEPEB), e do Grupo de Pesquisas e Estudos em Geografia da Infância (GRUPEGI)/Desmedicalização da Vida (UFF-UFJF). Currículo Lattes: http://lattes.cnpq.br/1900196360624425.
} 


\section{Introdução}

De acordo com o filósofo sul-coreano Byung-Chul Han (2015), cada época é responsável por criar/agravar maneiras de sofrer muito específicas, e o século XXI não está isento disso. Dentre as expressões de sofrimento características de nossos tempos, estão aquelas denominadas pelo saber médico como: TDAH, TEA, Transtornos de Ansiedade, Síndrome de Burnout, e, dentre muitas outras, a depressão.

Muito embora a depressão não se trate de um fenômeno moderno, o aumento de sua incidência nos últimos anos termina por inseri-la também na paisagem patológica do século XXI.

Em 2018, a Organização Pan-Americana de Saúde (OPAS) e a Organização Mundial de Saúde (OMS) publicaram uma folha informativa sobre a depressão com alguns dados interessantes. De acordo com o parecer elaborado pela OPAS/OMS (2018), 300 milhões de pessoas pelo mundo são acometidas de alguma forma por essa condição. É um fenômeno que alcança todas as idades, entretanto, as mulheres são mais atingidas do que os homens. Ainda de acordo com as organizações, estima-se que por ano, 800 mil pessoas se suicidem por causa da depressão.

Mas afinal, o que é a depressão? A "explicação oficial” para esse fenômeno é dada pela medicina, mais especificamente por uma especialidade médica: a psiquiatria. Partindo de uma leitura da principal nosografia psiquiátrica contemporânea - a quinta edição do Manual Diagnóstico e Estatístico de Transtornos Mentais (DSM-5) -, no capítulo denominado como Transtornos Depressivos, encontram-se oito tipos diferentes de depressão ${ }^{3}$, sendo que ambos apresentam como características comuns "a presença de humor triste, vazio ou irritável, acompanhado de alterações somáticas e cognitivas que afetam significativamente a capacidade de funcionamento do indivíduo. O que difere entre eles são os aspectos de duração, momento ou etiologia presumida" (APA, 2013, p. 199).

O fato desse fenômeno - ou fenômenos? - constar(em) nesse manual, indica duas coisas acerca da explicação médica sobre o mesmo: a primeira é que a medicina considera tais manifestações como patologias médicas, como transtornos mentais; e a segunda é que por se

\footnotetext{
${ }^{3}$ Transtorno disruptivo da desregulação do humor, transtorno depressivo maior (incluindo episódio depressivo maior), transtorno depressivo persistente (distimia), transtorno disfórico pré-menstrual, transtorno depressivo induzido por substância/medicamento, transtorno depressivo devido a outra condição médica, outro transtorno depressivo especificado e transtorno depressivo não especificado.
} 
tratar de uma manifestação patológica, certamente existe uma explicação biológica/fisiológica para esse fenômeno.

Serão essas explicações biológicas acerca da depressão que nos ocuparemos no primeiro momento desse texto. Entretanto, como veremos, tais narrativas médico-psiquiátricas acerca desses comportamentos que eles entendem como transtornos depressivos, são bastante inconsistentes, além de carecer de validação científica de fato.

É por compreender que a depressão é um fenômeno real, que tem colocado cada vez mais pessoas em condição de sofrimento e incapacidade no mundo (OPAS/OMS, 2018) e por entender que há inconsistências nessas explicações biológicas (WHITAKER, 2017), que um desafio se coloca diante de nós: pensar essas expressões de sofrimento através de olhares outros, e é justamente esse o objetivo desse texto.

É nessa busca por um outro viés - que não o psiquiátrico - que os saberes humanos, sobretudo, a filosofia, surgem como uma importante ferramenta interpretativa no que diz respeito à análise do fenômeno depressivo. Se olharmos para a depressão como sintoma de uma certa estruturação social, muitas outras possibilidades analíticas se abrem, não apenas sobre a depressão enquanto tal, mas também acerca do tipo de sociedade onde esse tipo de sofrimento surge e se prolifera.

Partindo dessa perspectiva, olhar para a depressão sem compreender como a nossa sociedade contemporânea se estrutura, carece de sentido. Portanto, no segundo momento desse texto, nos ocuparemos acerca dos olhares, tanto do filósofo Byung-Chul Han (1959), quanto do sociólogo polonês Zygmunt Bauman (1925-2017), acerca de nosso atual arranjo social marcado por um paradigma de positividade, por poderes des-subjetivados e pelos imperativos de desempenho e produtividade - e que tipo de subjetividade que ele gera.

Por fim, no terceiro momento desse texto, contaremos parte do mito grego de Eros e Psique, com o objetivo de ilustrar de que maneira a depressão é retratada na filosofia de Han. Isso nos dará uma base sólida para pensarmos o quanto a alta incidência contemporânea dessa condição de sofrimento, está mais relacionada com o modelo de configuração de nossa sociedade do que com a forma como nossos processos biológicos/neurológicos se configuram.

Comecemos então, expondo as explicações psiquiátricas/biológicas acerca da depressão.

\section{A hipótese serotoninérgica da depressão}


É muito comum vermos em bancas de jornais, revistas que anunciam em suas capas matérias ou artigos sobre os mecanismos neurológicos da depressão; programas de TV se orgulham em trazer grandes nomes da medicina para mostrar aos milhões de espectadores como a depressão age dentro do corpo e da cabeça, e também, para indicar quais profissionais procurar, quais tratamentos solicitar e que estilo de vida adotar ao perceber a presença de tal fenômeno; na internet cresce o número de brincadeiras em redes sociais - os chamados memes - que associam sintomas depressivos à neurotransmissores. O que todos esses exemplos têm em comum é a ideia de que a depressão tem um funcionamento biológico, ou mais especificamente, de que ela ocorre por causa de um déficit de serotonina no cérebro.

Essa perspectiva biológica sobre a depressão surge ainda no fim da década de 1960, quando a psiquiatria passava por um momento delicado em sua história. A falta de precisão nos diagnósticos, revelada pelas duas versões até então lançadas do DSM, expôs o quanto o saber psiquiátrico sofria para adaptar sua base epistemológica ao modelo racional-científico exigido pela medicina. Isso gerou críticas de todos os lados: da comunidade acadêmica, da científica e uma boa parte da sociedade. Para muitos, a psiquiatria carecia de credibilidade (AMARANTE \& FREITAS, 2017; WHITAKER, 2017).

$\mathrm{O}$ que permitiu que a psiquiatria começasse a se reerguer e que finalmente fosse respeitada como um saber científico, foi o avanço da psicofarmacologia e das neurociências. $\mathrm{O}$ desenvolvimento desses saberes possibilitou que a psiquiatria começasse a fazer uso de explicações biológicas/neurológicas para os ditos fenômenos psicopatológicos, dentre eles, a depressão. Isso contribuiu para uma adequação do saber psiquiátrico diante dos cânones da medicina (WHITAKER, 2017).

A hipótese biológica da depressão surge a partir de estudos e pesquisas elaboradas pelo psiquiatra norte-americano, Joseph Schildkraut (1934-2006). Entretanto, antes de mostrarmos os caminhos trilhados pelo psiquiatra e suas respectivas conclusões, faz-se necessário mostrar um breve panorama acerca do funcionamento cerebral.

O sistema de transmissão de mensagens no cérebro humano tem um mecanismo fascinante: ao todo temos aproximadamente cem bilhões de neurônios; um neurônio característico possui dendritos, axônio, bainha de mielina, entre outras coisas, em seu corpo celular; através de seus dendritos ele recebe informações, e através de seu axônio ele repassa as mesmas; um axônio possui várias ramificações que possibilitam a liberação dos neurotransmissores - que são substâncias químicas - na fenda sináptica; a fenda sináptica é um espaço manométrico que separa dois neurônios. De acordo com Whitaker (2017, p. 81), um 
"único neurônio tem entre mil e dez mil conexões sinápticas, e o cérebro adulto tem ao todo uns 150 trilhões de sinapses".

Dito isso, a teoria de que as ditas psicopatologias são doenças biológicas/neurológicas consiste, basicamente, na ideia de que há um desajuste na liberação/recepção desses neurotransmissores na fenda sináptica por parte dos neurônios. No caso da depressão, especificamente, o que é dito, de acordo com essa hipótese, é que há uma atividade deficitária nas vias serotoninérgicas cerebrais. Portanto, o neurotransmissor associado ao comportamento depressivo é a serotonina (WHITAKER, 2017).

Essa conclusão surge a partir de estudos com a iproniazida e imipramina, realizados pelo já citado Schildkraut. O psiquiatra percebeu que a remoção dos neurotransmissores nas fendas sinápticas acontecia de duas formas diferentes: “ou a substância química era recaptada pelo neurônio pré-sináptico e restaurada para uso posterior, ou era metabolizada por uma enzima e descartada como resíduo" (WHITAKER, 2017, p. 84).

Schildkraut descobriu que esse processo de metabolização transformava a serotonina em ácido 5-hidroxi-indolacético (5HIAA). Essa informação foi essencial, na medida em que, dava para se ter acesso a esse metabólito através do líquido cefalorraquidiano. Se é verdade que a depressão ocorria devido à uma baixa atividade/produção serotoninérgica nas fendas sinápticas, isso poderia ser comprovado através do nível baixo de 5-HIAA encontrado no líquido cefalorraquidiano de uma pessoa depressiva.

Partindo dessa premissa, vários pesquisadores desenvolveram diversos estudos e testes, buscando a validade dessa hipótese neuroquímica dos sintomas depressivos. Entre os anos de 1969 e 1973, testes com pessoas deprimidas foram feitos, principalmente nos EUA, mas boa parte deles não tiveram resultados significantes que pudessem comprovar a relação entre o déficit de 5-HIAA e a depressão ${ }^{4}$.

Em 1974, quando essa hipótese estava à beira de ser dada como morta, pesquisadores do Instituto Karolinska, em Estocolmo, dirigidos por Marie Asberg (1938), trouxeram essa ideia à tona novamente: "Vinte dos 68 pacientes deprimidos testados por eles sofriam níveis baixos de 5-HIAA, e esses pacientes com baixa serotonina eram um pouco mais suicidas que os outros, sendo que dois dos vinte acabaram se suicidando" (WHITAKER, 2017, p. 85).

Esse estudo contribuiu para que houvesse uma nova propagação da teoria que relacionava a baixa quantidade de serotonina ao comportamento depressivo. Rapidamente

\footnotetext{
${ }^{4}$ Ver AMARANTE, P.; FREITAS, F. (2017); WHITAKER, R. (2017).
} 
psiquiatras norte-americanos espalharam que uma parcela considerável de seus pacientes depressivos apresentava um baixo nível de serotonina no cérebro. Entretanto, de acordo com Whitaker (2017, p. 86), ao olhar esse estudo sueco hoje em dia, é possível perceber como os pesquisadores de Estocolmo acabaram confundindo seus próprios desejos com a realidade, culminando em uma apresentação de dados tendenciosos:

Em seu estudo, Asberg relatou que $25 \%$ de seu grupo "normal" tinham níveis cefalorraquidianos de 5-HIAA abaixo de 15 nanogramas por mililitro. Cinquenta por cento tinham de 15 a 25 nanogramas de 5HIAA por mililitro, e os $25 \%$ restantes tinham níveis acima de 25 nanogramas. A curva em forma de sino de seus sujeitos "normais" mostrou que os níveis de 5-HIAA eram bastante variáveis. Mas o que Asberg não observou em sua discussão foi que a curva de distribuição normal dos 68 pacientes deprimidos de seu estudo era quase idêntica. Vinte e nove por cento ( 20 dos 68 ) tinham contagens de 5-HIAA abaixo de 15 nanogramas, $47 \%$ tinham níveis entre 15 e 25 nanogramas, e $24 \%$ tinham níveis acima de 25 nanogramas. Vinte e nove por cento dos pacientes deprimidos podiam ter níveis "baixos" de metabólitos de serotonina no líquido cefalorraquidiano (esse era o "subgrupo biológico" da investigadora), mas, por outro lado, o mesmo acontecia com $25 \%$ das pessoas "normais". O nível médio dos normais era de 20 nanogramas e, como se constatou, mais da metade dos pacientes deprimidos - 37 em 68 - tinham níveis superiores a esse valor.

A explicação serotoninérgica da depressão foi investigada mais algumas vezes ao longo dos anos 90 e 2000 pelo National Institute of Mental Health (NIMH), porém em praticamente nenhum desses estudos foram encontradas evidências suficientes que pudessem comprová-la. Com isso, era de se esperar que essa teoria fosse abandonada, mas não é o que acontece.

A psiquiatria adota a teoria dos desequilíbrios químicos de tal forma, que boa parte do saber psiquiátrico passa por uma reestruturação. Dessa forma, não somente o olhar acerca da depressão, mas das psicopatologias de maneira geral, sofre uma mudança. Isso ocorre, sobretudo, por vontade/necessidade da psiquiatria, de se tornar científica e deixar de ser, de uma vez por todas, marginalizada pela medicina.

Outro motivo seria o advento e a propagação da psicofarmacologia: na medida em que os psicofármacos, que estavam surgindo por toda a parte, "tratavam" as psicopatologias através de compostos químicos que agiam sobre o cérebro, deveria ser neste que as causas e funcionamentos das patologias mentais deveriam ser buscados (WHITAKER, 2017).

Com a hipótese dos desequilíbrios químicos, juntamente com a possibilidade de um tratamento psicofarmacológico, os olhares sobre a depressão puderam se descolar do campo 
social/moral e migrarem para a biologia, além de contribuírem para a consolidação da psiquiatria como um saber científico, nos moldes de outras especialidades médicas.

O DSM-III, manual lançado em 1980, é a síntese de toda essa lógica, e um produto genuíno de seu tempo histórico e de sua cultura. Ele apresenta um prisma biológico sobre suas categorias diagnósticas e estabelece uma nova prática terapêutica: o tratamento por medicamentos psiquiátricos. Nasce assim, uma espécie de dialética que põe as psicopatologias em relação constante com os psicofármacos: a depressão - entre outros transtornos mentais seria resultado de um desequilíbrio neuroquímico que os - assim chamados - antidepressivos prometiam reequilibrar.

Dessa forma, os caminhos da psiquiatria e o da indústria farmacêutica se cruzam, gerando uma aliança que vai beirar a promiscuidade, principalmente se levarmos em consideração o quão rentável se tornou, para ambos os lados, associar a depressão a fatores biológicos (WHITAKER, 2017).

Acontece que, as narrativas psiquiátricas não se constroem a partir das evidências cientificas. O que Amarante e Freitas (2017) nos demonstram é que ocorre justamente o contrário: estudos científicos, pesquisas e testes são burlados para poderem se adequar ao discurso psiquiátrico. As perspectivas da psiquiatria acerca de suas psicopatologias - dentre elas, a depressão - dependem de muitos interesses. Enquanto a psiquiatria busca por poder, a indústria farmacêutica está atrás de lucro.

Por essa razão que, por mais incomprovada que seja tal hipótese, ainda hoje podemos presenciar tantas pessoas falando sobre ela na TV, na internet, nas revistas e até nas universidades. Fato é, que enquanto essa teoria continuar gerando lucros exorbitantes para médicos psiquiatras e empresários, não haverá um menor esforço, por parte dos mesmos, para refutá-la ou abandoná-la.

Muito embora, essas narrativas psiquiátricas acerca da depressão sejam falaciosas, é inegável o avanço dessa condição de sofrimento na contemporaneidade. Por motivos óbvios, estamos impossibilitados de pensar a incidência vertiginosa da depressão pelo mundo em nossos tempos, como uma epidemia ou pandemia de déficit de serotonina, o que nos coloca diante da seguinte questão: por que o número de pessoas atingidas pela depressão cresce descontroladamente? A inviabilidade de buscar as possíveis causas da depressão e de sua propagação no corpo do sujeito depressivo, nos leva a procurar respostas para essa questão, fora do corpo desse individuo, ou seja, no contexto social em que ele vive e existe. 


\section{O processo de positivação da sociedade e o surgimento do sujeito do desempenho}

De acordo com Han (2017b), as sociedades do século XX e XXI se estruturam de formas distintas, e até opostas: enquanto a primeira é marcada por sanções negativas, a segunda vai se positivando cada vez mais. Entretanto, faz-se necessário esclarecer uma questão: quando o autor usa expressões como sanções positivas e negativas, ou positividade e negatividade, ele não está fazendo uso das representações comuns desses termos.

A negatividade da qual Han $(2017 \mathrm{a} ; 2017 \mathrm{~b} ; 2015)$ se refere, diz respeito a um conjunto de relações compostas por duas figuras bem distintas e identificáveis, onde uma exerce influência sobre a outra. É isso que possibilita o surgimento de relações dicotômicas manifestadas por pares opostos, tais como: amigo e inimigo, dentro e fora, senhor e escravo, normal e patológico, entre outras. Onde há negatividade, as atitudes são sempre voltadas ao outro, sejam elas em forma de sentimento, emoção, desejo e/ou repulsa. A negatividade é o lugar por excelência do outro, em toda a sua alteridade e estranheza.

O principal parâmetro de negatividade da qual Han $(2018 ; 2017 b$; 2015) tira como exemplo, é o modelo de sociedade da disciplina, conceito discutido em diversas obras de Michel Foucault (1926-1984) - filósofo francês que, por vezes, indica como paradigma disciplinar, o poder e as práticas exercidas pela psiquiatria.

A biologização dos fenômenos ditos psicopatológicos, tais como a depressão conforme apresentado por nós no tópico anterior - é apenas uma reestruturação de uma prática psiquiátrica antiga: a medicalização ${ }^{5}$ dos corpos. De acordo com Foucault (2006), a psiquiatria, enquanto condição médica, desde Philippe Pinel (1745-1826) - considerado por muitos, o precursor da psiquiatria moderna - atua como poder antes mesmo de funcionar como saber.

Nos hospícios construídos para os - assim chamados - alienados, requeria-se a vigilância, pois está era entendida como sustentáculo fundamental para o tratamento, no sentido de que, sem ela não era possível obter as "observações exatas" e a "cura permanente". Para tanto, são necessárias duas coisas: disciplina e ordem, ou, em outras palavras, uma regularidade que se operava no próprio interior dos corpos.

Para Foucault (2006, p. 5), o olhar médico-psiquiátrico e tudo que nele comporta, devido sua constituição na qualidade de saber, tem por condição concreta uma "certa relação de ordem,

\footnotetext{
${ }^{5}$ De acordo com Amarante e Freitas (2017, p. 14), medicalização “configura-se como o processo de transformar experiências consideradas indesejáveis ou perturbadoras em objetos da saúde, permitindo a transposição do que originalmente é da ordem do social, moral ou político para os domínios da ordem médica e práticas afins".
} 
certa distribuição do tempo, do espaço, dos [...] corpos, dos gestos, dos comportamentos, do discurso". Isto é, a relação do olhar médico com seu "objeto" é uma relação de ordem disciplinar. A terapêutica, portanto, é a objetividade que acontece dentro desse arranjo de distribuição regrada do poder, onde o interno é reificado e apropriado pelo poder-saber psiquiátrico. É esse tipo de relação disciplinar que Han $(2018 ; 2017 b$; 2015) toma como paradigma de negatividade.

O conceito de positividade já é um pouco mais complexo de ser entendido, pois não se trata mais de uma relação entre duas figuras bem distintas. Aquilo que representava o outro na negatividade, é interiorizado pelo $e u$ na positividade. Portanto, as ações que eram dirigidas ao outro, acabam se voltando para si mesmo, se tornando assim, autorreferentes. Logo, elas têm como destino final, o mesmo ponto de partida: o próprio eu. Na positividade não há lugar para o outro, para sua estranheza e/ou alteridade, pois o mundo se torna uma extensão/projeção desse $e u$ (HAN, 2017a).

Dessa forma, com a eliminação da alteridade/estranheza, a positividade acaba por nivelar tudo ao igual. Enquanto a negatividade se caracteriza pela alteridade/estranheza do outro, a positividade, por sua vez, vai se particularizar pelo excesso do igual (HAN, 2019; 2017a).

Dizíamos que a sociedade do século XXI é bem diferente, se comparada com a do século $\mathrm{XX}$. Isso porque, enquanto a sociedade do século passado se estruturava a partir de esquemas de negatividade, a nossa sociedade contemporânea apresenta muito mais traços de positividade - a própria transposição que a psiquiatria faz do campo da moral para o campo da biologia/neurologia, tal como foi exposto no tópico anterior, é um exemplo dessa mudança. Mas o que ocorre na sociedade entre os séculos XX e XXI, que desencadeia essa mudança topológica nas formas de estruturação social?

Para Han (2018), o neoliberalismo está profundamente associado ao processo de positivação da sociedade, na medida em que, um estado de coisas atravessado por esquemas de positividade é fundamental para o estabelecimento do projeto de poder neoliberal. O que ocorre é que o neoliberalismo é uma doutrina econômica/filosófica cujos pilares são: a desregulamentação/liberdade dos mercados e o enfraquecimento do poder do Estado, que por se tratar de uma instância de poder autoritária, sempre exerceu sua soberania através da negatividade.

Com o mercado enquanto soberano ao invés do Estado, o neoliberalismo consegue a autonomia que precisa para inaugurar na sociedade, uma nova forma de controle social. A nova 
ordem criada e estabelecida pelo poder e políticas neoliberais, não controlam mais a sociedade por meio da negatividade da repressão, como sempre fez o Estado, e sim, pela positividade da liberdade. Assim, as sanções negativas caracterizadas pela privação da liberdade, violências, ameaças, ordens e disciplina, dão lugar ao apelo à motivação, e ao incentivo. A positividade transforma o verbo tu deves em tu podes (HAN, 2018; 2017a; BAUMAN, 2008; 2001).

Esse efeito é atingido devido à forma característica do mercado de se exercer a soberania. Vale lembrar que o Estado, por agir de forma regulamentadora, vê sua liberdade de ação se esbarrar em seus próprios processos burocráticos. Além disso, o Estado é representado por figuras em seus mais diversos níveis - legislativo, executivo e/ou judiciário -, o que faz com ele se fixe em estruturas, tais como grandes prédios/construções e em volumosas constituições (BAUMAN, 2008).

Por entender esse modelo de gestão como anacrônico e ineficiente, o mercado estabelece sua representação, não em figuras de poder e autoridade, mas sim em lógicas e mecanismos, sobretudo, de consumo, de desempenho e de otimização. Dessa forma, o poder do mercado transita de maneira fluida entre os espaços, ao invés de residir neles de maneira fixa. O mundo projetado pelo neoliberalismo busca ser livre de qualquer obstáculo que possa restringir a liberdade, mas não dos indivíduos como é comumente dito, e sim, dessas já citadas lógicas de mercado. (HAN, 2018; BAUMAN, 2008; 2001).

A liberdade para os indivíduos, prometida pelo neoliberalismo através de ações que promovem a livre iniciativa, não passa de uma técnica de controle, que explora a população de maneira tanto eficiente, quanto sutil. Essa exploração neoliberal não ocorre no plano da negatividade, o que quer dizer que não se trata de uma ação que envolva duas figuras distintas e bem identificáveis, ou seja, não há um eu que explora o outro, ou é explorado por ele. A exploração neoliberal se caracteriza por sua positividade: formas de organização social que conduzem o eu à uma autoexploração voluntária, sem precisar que algo ou alguém lhe obrigue a isso. Assim, o neoliberalismo substitui a exploração alheia, pela exploração autorreferente (HAN, 2018).

Isso acontece devido ao fato de a soberania do mercado ser representada por lógicas, ao invés de figuras de poder e autoridade, permitindo assim, que os poderes do mercado se tornem des-subjetivados e possam residir no anonimato.

A soma de todos esses fatores, provocam no sujeito dessa sociedade neoliberal, uma profunda sensação de liberdade, na medida em que, esse sujeito não enxerga mais o Estado que sempre agiu de maneira autoritária e disciplinar - como uma grande ameaça à sua 
existência; nem tampouco percebe as técnicas de dominação social do mercado, que por agir tão silenciosa quanto anonimamente, por vezes dá até impressão de não agir, ou de até mesmo não existir.

Dessa forma, esse sujeito passa a acreditar que está livre de toda e qualquer coerção e violência externa, e que finalmente é senhor de si mesmo. Essa sensação de liberdade será profundamente explorada pelo neoliberalismo, tendo em vista que, quanto mais livre esse sujeito acredite ser, em mais desamparo ele se encontra (HAN, 2018).

Esse desamparo surge, pois, ao fazer com que o outro, que oprime e violenta, desapareça, o neoliberalismo elimina também qualquer possibilidade de atribuição de culpa/responsabilidade a esse outro, deixando apenas o eu como medida de todas as coisas. Em outras palavras, nessa sociedade neoliberal, a sensação de liberdade transforma o eu em um sujeito do desamparo ao fazer desaparecer todas as causas externas/sociais, assim como as contradições sistêmicas também, o que automaticamente, termina por colocar esse $e u$ na posição de único culpado/responsável por todos os fracassos em potencial (HAN, 2018; BAUMAN, 2001).

Podemos perceber, a partir disso, o quanto o binômio liberdade-desamparo está no cerne dos mecanismos neoliberais de positivação da sociedade. A falta de ter algo ou alguém para responsabilizar ou agradecer, é um fardo enorme para esse sujeito neoliberal. Abandonado às suas próprias iniciativas e levado a acreditar que não há saídas que não partam dele próprio, esse sujeito se força a buscar soluções individuais para problemas que são sistêmicos, como a desigualdade social e o desemprego, por exemplo. Todas essas soluções são encontradas em um mais de produtividade, desempenho, otimização e consumo, o que termina por se mostrar muito conveniente para os poderes neoliberais.

Com as constantes crises que são características das sociedades capitalistas/neoliberais, esse sujeito se percebe mais perto do fracasso do que do sucesso, o que contribui para o desenvolvimento de uma certa quantidade de medo e insegurança. Entretanto, com o acumulo de crises, que ocorrem em diversas esferas, tanto públicas quanto privadas, essas sensações de medo e insegurança passam de situações excepcionais para situações recorrentes, tornando-as espectros recorrentes na vida desse sujeito. A estratégia proposta de maneira muito sutil pelos poderes neoliberais, para que o indivíduo se livre desse espectro de medo e insegurança, e que ao mesmo tempo, contribui para resolver as crises de nossa sociedade - crises essas, que por essência, são irresolvíveis, como nos aponta Klein (2008) -, é sempre apresentar mais 
desempenho, mais produtividade, e se isso significar mais otimização e mais consumo, melhor ainda.

Assim, de mais em mais, o que surge como uma estratégia biográfica e individual para lidar com as contradições sistêmicas e sociais, vai se tornando aos poucos, uma necessidade imperiosa e autoimposta de desempenho (HAN, 2018; BAUMAN, 2001).

Esse imperativo de desempenho se apropria da vida do sujeito em sua totalidade, por vezes, confunde-se até com um traço de personalidade. Tudo que o indivíduo faz, precisa ser feito em mais quantidade e em melhor qualidade. Surge uma cobrança interna, que faz com que esse sujeito esteja sempre pensando em algo que não está sendo feito, mas que deveria. Dessa forma, não apenas o mundo do trabalho, mas o mundo das relações humanas, dos estudos, das realizações, e até mesmo os momentos de lazer e folga, estão submetidos às lógicas do desempenho (HAN, 2018; 2017a).

O sujeito de desempenho, por acreditar que está se realizando, termina por se explorar de maneira voluntária e indiscriminada. Sua constante cobrança sobre si mesmo, torna as figuras do algoz, do senhor e do explorador, anacrônicas. $\mathrm{O}$ neoliberalismo vende a ideia de formar uma sociedade feita de senhores de si mesmos, mas na verdade, o que formam é uma legião de escravos de si mesmos.

Com a des-subjetivação dos poderes que regulamentam a sociedade, mais a eliminação do outro a quem se poderia culpar ou agradecer, somado com a redução da existência social do sujeito ao seu próprio $e u$, o neoliberalismo consegue estabelecer de maneira muito eficiente, um processo de positivação da sociedade. A cobrança, exploração e vigilância que vinham do outro da negatividade, agora vem do $e u$ em direção a si próprio. É por esse motivo que Han (2018; 2017b) diz que: primeiro, a sociedade neoliberal é o lugar por excelência dos esquemas de positividade; e segundo, que essa positividade não elimina a violência, apenas a desloca para espaços subcutâneos, ou em outras palavras, se torna autorreferente.

A positividade é essencial ao neoliberalismo, pois é através dela que duas coisas muito importantes acontecem: a primeira é a elevação da produtividade, e a segunda são as forças do mercado, que ficam desobrigadas do dever de cobrar e vigiar, deixando-as livres para outros fins (HAN, 2018; BAUMAN, 2008).

Acontece que, quando os poderes neoliberais surgem na sociedade, encontram um modelo de dominação social ultrapassado e até determinado ponto, ineficiente. Isso porque a exploração alheia, característica da sociedade do século XX, totalmente negativada, se mostrou problemática, por três fatores, principalmente: $\mathrm{O}$ primeiro deles é que explorar o sujeito contra 
a vontade dele, naturalmente limita sua produtividade, por mais coagido a produzir que ele seja; o segundo fator é que esse tipo de dominação exige um grande esforço não apenas do dominado, mas do dominador também, que precisa investir em recursos de vigilância e em métodos punitivos/ameaçadores para quem sair das regras; e o terceiro fator é que, por se tratar de uma exploração contra a vontade do sujeito, e por haver tanto esforço para transmitir autoridade e exigir disciplina, esse tipo de poder que domina pela negatividade, chama a atenção para si mesmo e inspira revoluções e resistências, ou seja, é um poder com um "alvo nas costas".

Não é o que acontece na sociedade neoliberal da positividade: a produtividade não esbarra em limites, na medida em que o sujeito se explora descontroladamente, e faz isso na crença de que é o que deve ser feito; a des-subjetivação/anonimato dos poderes não os deixam mais expostos à qualquer tipo de resistência - não havendo quem culpar, toda a indignação do sujeito, se volta contra si mesmo; e por último, não é mais necessário altos investimentos em agentes/órgãos reguladores e nem em estratégias de cobrança, punição e vigilância, na medida em que, é o próprio sujeito que se cobra, se explora, se vigia e se puni, e cada vez em maior quantidade.

Apesar dessa análise do sujeito/comportamento neoliberal ser uma problemática quase que central na obra de Han, o filósofo sul-coreano não é o primeiro a trazer essa questão para o centro do debate. Foucault, por exemplo, ainda no fim da década de 1970, já se atentava ao movimento de apropriação da vida humana que o neoliberalismo vinha fazendo.

De acordo com Foucault (2008, p. 332), o neoliberalismo é responsável por generalizar na sociedade o modelo-empresa, ou seja, as lógicas empresariais, manifestadas através de binômios como oferta-procura e custo-lucro, se transformam em arquétipos de relações sociais, a saber, "do indivíduo consigo mesmo, com o tempo, com seu círculo, com o futuro, com o grupo, com a família”.

Foucault (2008) traz então para o debate, o conceito de homo oeconomicus, para, justamente, tentar explicar o tipo de sujeito/comportamento que surge e se molda a partir do neoliberalismo. O homo oeconomicus, na filosofia de Foucault (2008, p. 369), é

aquele que aceita a realidade ou que responde sistematicamente às modificações nas variáveis do meio, esse homo oeconomicus aparece justamente como o que é manejável, o que vai responder sistematicamente a modificações sistemáticas que serão introduzidas artificialmente no meio. O homo oeconomicus é aquele que é eminentemente governável. 
Esse homo oeconomicus encontra no ato do consumo uma atividade, também, de produção, na medida em que, ao consumir, ele produz sua própria satisfação. Dessa forma, o comportamento consumista pode ser entendido como uma atividade empresarial, o que faz com que esse homo oeconomicus - assim como o sujeito do desempenho - seja um empresário de si mesmo, ou que pelo menos acredita ser.

Tendo em vista essa narrativa foucaultiana, se a satisfação é tanto uma mercadoria quanto um produto, e que é tanto consumida quanto produzida pelo mesmo sujeito, não é insensato pensar que o homo oeconomicus vive também sob o jugo do imperativo de desempenho, na medida em que, depende de seus próprios esforços físicos/financeiros para produzir/consumir sua própria satisfação.

O cenário social que se desenha a partir dessa configuração, é caracterizado, de um lado, por pequenos grupos - que habitam nas camadas superiores da hierarquia social - que nunca viram tanta produtividade, e por conseguinte, tanto lucro; e por outro lado, de um número cada vez maior de pessoas que estão isoladas no si-mesmo da positividade, que sofrem de diversas maneiras, ou por tentarem atingir um cota de desempenho e produtividade que é inatingível, ou por não conseguirem realizar tal feito (HAN, 2018).

Os modelos de gestão neoliberais, somados com esses esquemas de positividade, produzem consequências desastrosas para a subjetividade dos indivíduos inseridos nesse arranjo social. A depressão surge de maneira muito forte, como um sintoma e como um indicativo dessas lógicas de autoexploração e de busca por mais desempenho e produtividade.

Em Psicopolítica - o neoliberalismo e as novas técnicas de poder (2018, p. 16), Han afirma que "no regime neoliberal de autoexploração, a agressão é dirigida contra nós mesmos. Ela não transforma os explorados em revolucionários, mas sim em depressivos”. E em Sociedade do Cansaço (2015, p. 25), o autor diz que a "sociedade do desempenho, [...] produz depressivos e fracassados".

\section{A erosão do outro e o infarto psíquico: o sofrimento do sujeito do desempenho a} partir do mito de Eros e Psique

Depois de trair a confiança de seu amado Eros, e julgá-lo um monstro, a bela e jovem Psique, inconsolável, atira-se em um rio esperando a própria morte. Contudo, as águas do rio, de maneira muito cortês, a leva até a margem. O deus dos campos, Pã, lhe impeliu que 
obliterasse o que havia acontecido e partisse ao encontro de Eros para recobrar dele seu amor (BULFINCH, 2014).

Psique disposta a recuperar o amor e a confiança de Eros, vagou dias e noites por toda terra em sua procura. Depois de tanto, chegou em um templo no alto de uma montanha, e ao adentrá-lo, deparou-se com uma desmedida bagunça de grãos de trigo e cevada que se encontravam espalhados por todo o santuário. Psique não intentando negligenciar o culto a nenhuma divindade, pôs-se a ordenar as coisas, e as colocou cada qual em seu lugar. Deméter, deusa à qual o tempo era destinado, grata pela atitude de Psique, a ensinou como poderia livrarse da ira de Afrodite, deusa do amor, da beleza e do sexo, e mãe de Eros.

Ao receber Psique, Afrodite não encobre sua fúria. Como condição para ser perdoada, impôs a Psique uma série de obrigações que deveriam ser realizadas. No entanto, as tarefas projetadas por Afrodite eram tão árduas que poderiam causar sua morte.

Embora Psique tenha passado pelas três primeiras tarefas, demonstrando assim, seu grande amor por Eros, ainda faltava uma última, que todavia guardava um destino mortal: Psique teria de descer ao mundo dos mortos e pedir à deusa do submundo, Perséfone, que lhe brindasse com um pouco de sua beleza, e guardasse em uma caixa. Quando Psique estava ao topo de uma elevada torre, pronta a se atirar para alcançar o submundo, a própria torre lhe sussurrou um caminho e os segredos para chegar até o reino de Hades. Além disso, a instruiu para que não olhasse dentro da caixa, pois os olhos dos mortais não estariam preparados para a beleza dos deuses. Seguindo tais conselhos, Psique teve êxito em sua última tarefa, mas sua insistente curiosidade não lhe permitiu permanecer com a caixa fechada. Ao abrir, desejando ver o que nela havia, encontrou lá um sono terrível que dela se apossou (BULFINCH, 2014).

Eros que havia se curado de sua ferida, voou ao socorro de Psique, colocou o sono novamente na caixa e a salvou. Psique poderia, portanto, se apresentar a Afrodite e conquistarlhe seu perdão. Eros solicitou a ajuda de Zeus para pacificar a ira de Afrodite e harmonizar seu casamento com Psique. O grande deus do Olimpo, aceitando o pedido de Eros, oferece a Psique a taça de ambrosia. Sucedendo toda cerimônia, Eros e Psique casaram-se, e como fruto desse amor nasceu Voluptas, deus do prazer.

$\mathrm{O}$ amor transcendental e transgressor presente e representado em um dos mitos mais aprazíveis da mitologia grega - o mito de Eros e Psique -, onde a vulnerabilidade do eu é totalmente exposta diante do outro, aparenta estar um tanto quanto distante de nosso tempo. Aqui, nos contornos de uma sociedade neoliberal, positivada, o encontramos em uma crise profunda, em uma evidente agonia (HAN, 2017a). 
A estruturação social de nosso tempo, desenhada por traços de positividade - onde o $e u$, é o principal eixo de valor e o mais de desempenho é o imperativo que baliza a existência humana - é uma organização da qual o eros/amor desaparece lentamente. A sociedade positivada transforma o amor em um objeto de consumo e o reduz a uma apuração hedonista. A cupidez do outro dá lugar a comodidade do igual: "O que se busca é o confortável, em última instância, a espessa imanência do igual. Ao amor hodierno falta toda e qualquer transcendência e transgressão" (HAN, 2017a, p. 40).

As mudanças topológicas que sofremos na emergência de uma organização social positivada, faz germinar uma cultura de comparação constante. Estamos frequentemente comparando tudo com tudo, e terminamos por nivelar tudo ao igual. É nesse nivelamento que a paisagem relacional com o outro se altera: perdemos de vista justamente a vivência da atopia do outro, e perdemos, por consequência, o sentido da alteridade e da estranheza provocada por ele, na medida em que, tudo recai em uma busca incessante pelo igual.

Eliminar essa alteridade e estranheza é mesmo o pendor de nossa sociedade positivada, como afirma Han (2017a, p. 9, grifo do autor):

Assim, a tendência da sociedade de consumo é eliminar a alteridade atópica em prol de diferenças consumíveis, sim, heterotópicas. A diferença é uma positividade em contraposição à alteridade. Hoje, a negatividade está desaparecendo por todo lado. Tudo é nivelado e se transforma em objeto de consumo.

Como produto de uma organização positivada, nossa sociedade vai se tornando cada vez mais uma sociedade narcísica, ou seja, o investimento libidinal dos sujeitos desse tipo de sociedade, se concentram fundamentalmente na própria subjetividade. É necessário dizer, entretanto, que o narcisismo para Han (2017a) não tem relação com um excesso de amor próprio, mas sim, que esse sujeito narcisificado não consegue estabelecer claramente os limites de si próprio. O desaparecimento do outro - questão central dessa crise do eros - ocorre, sobretudo, pelo evento narcísico que não permite que um indivíduo estabeleça limites entre ele mesmo e o outro, e, como consequência, esse último desaparece.

O outro que desaparece no processo de positivação da sociedade, não diz respeito apenas àquelas figuras de poder e autoridade que restringiam a liberdade do eu e o violentavam. $\mathrm{O}$ desaparecimento do outro é um fenômeno que ocorre em todos os domínios da vida, contribuindo para o que Han (2017a) chama de narcisificação de si-mesmo, e produzindo também, uma verdadeira crise do eros. 
Como o investimento em sua própria subjetividade é primordial, para esse sujeito, “o mundo se lhe afigura como sombreamentos projetados de si mesmo" (HAN, 2017a, p. 10). O outro desaparece uma vez que o sujeito

não consegue perceber o outro em sua alteridade e reconhecer essa alteridade. Ele só encontra significação ali onde consegue reconhecer de algum modo a si mesmo. Vagueia aleatoriamente nas sombras de si mesmo até que se afoga em si mesmo. (HAN, 2017a, p. 10).

É exatamente aqui, na análise das conjunturas dessa sociedade positivada e do tipo de subjetividade que ela faz emergir, que a filosofia de Byung-Chul Han surge como uma possibilidade interessante de pensar a depressão, bem na lacuna deixada de lado pela psiquiatria. Han (2018; 2017a; 2017b; 2015) nos oferece a possibilidade de pensar a depressão enquanto um sintoma de nossa sociedade.

A depressão é uma enfermidade narcísica, afirma Han (2017a), o que origina e/ou produz a depressão é - por um lado - uma relação conturbada do sujeito contemporâneo consigo mesmo, uma relação completamente sobrecarregada e marcada num controle desmoderado e “doentio". Em nosso horizonte histórico, esse sujeito depressivo-narcísico está esgotado e fadigado de si mesmo, dado a erosão/desaparecimento do outro, processo esse que é dramático e "fatalmente avança de modo sorrateiro e pouco perceptível" (HAN, 2017a, p. 8).

A depressão, desse modo, é herdeira da crise do eros, na medida em que, este e aquele são antagônicos. O eros contrapõe-se diretamente a depressão, visto que, o eros é aquele que arranca o sujeito de si mesmo e direciona ao outro, assim como retratado no mito de Eros e Psique. É o eros que leva o $e u$ até o outro. Nesse encontro, tem-se a alteridade. Contudo, a nãoalteridade leva o sujeito - que já está esgotado de si mesmo - a mergulhar mais ainda em si, fazendo com que o outro continue desaparecendo em grande medida. Assim, seria a soma da ausência do outro enquanto ser-de-alteridade e ser-de-estranheza, a ausência da diferença não indiferente e a ausência do afetamento para com o outro, os elementos primordiais da depressão (HAN, 2017a; PONZIO, 2010).

O sujeito contemporâneo, voltado narcisicamente para o desempenho e em busca de sucesso e bons resultados, vive em um estado de mero viver. Estes portam consigo uma confirmação de um pelo outro: “Ali, o outro, que é privado de sua alteridade, degrada-se em espelho de um, que confirma a esse em seu ego" (HAN, 2017a, p. 11). Essa racionalidade de reconhecimento embaraça o sujeito narcísico do desempenho de uma forma ainda mais alargada 
em si mesmo. O resultado disso é uma depressão do sucesso. Para Han (2017a, p. 11, grifo do autor):

O sujeito do desempenho depressivo mergulha e se afoga em si mesmo. $\mathrm{O}$ eros, ao contrário, possibilita uma experiência do outro em sua alteridade, que o resgata de seu inferno narcisista. Ele dá curso a uma denegação espontânea do si mesmo, um esvaziamento voluntário do si mesmo. Um sujeito do amor é tomado por um tornar-se-fraco todo próprio, que vem acompanhado ao mesmo tempo por um sentimento de fortaleza. Mas esse sentimento não é o desempenho próprio de si mesmo, mas o dom do outro.

A depressão enquanto sintoma social, se manifesta como impedimento da alteridade e do modo de ser e estar no mundo do sujeito do desempenho. Dessa maneira, a depressão - por outro lado - para Han (2015), é também uma depressão do esgotamento, causada por uma pressão por desempenho. Logo, o que torna o sujeito contemporâneo depressivo - além de viver afogado em si mesmo, em um arranjo social que elimina a figura do outro - é o imperativo de desempenho como um novo dever social da sociedade contemporânea:

O homem depressivo é aquele animal laborans que explora a si mesmo e, quiçá deliberadamente, sem qualquer coação estranha. É agressor e vítima ao mesmo tempo. [...] Mas a depressão [...] irrompe no momento em que o sujeito de desempenho não pode mais poder. Ela é de princípio um cansaço de fazer e de poder. A lamúria do indivíduo depressivo de que nada é possível só se torna possível numa sociedade que crê que nada é impossível (HAN, 2015, p. 28,29 , grifo do autor).

O indivíduo contemporâneo não consegue sair incólume depois de ser atravessado pela pressão por desempenho e pela violência da autoexploração ilimitada. O sujeito do desempenho encontra-se em uma guerra que é autorreferente, e o depressivo é, precisamente, o "inválido" desse conflito: ele se explora e se cobra até o esgotamento profundo. Esse desempenho excessivo causa um infarto na psique desse sujeito que, mergulhado em si mesmo, em si se afoga (HAN, 2017a; 2015).

A depressão é, sobretudo, uma condição de sofrimento característico de uma sociedade marcada pelo excesso de positividade, refletindo uma coletividade que está em constante conflito consigo mesmo, situação da qual, apenas o encontro dialógico com o outro pode nos livrar (HAN, 2017a; 2015; MIOTELLO, 2018), ou nas palavras de Han (2017a, p. 12, grifo do autor): "O eros vence a depressão".

\section{Considerações finais}


Para concluir, alguns pontos precisam ser considerados: primeiramente, as discussões levantadas nesse artigo não têm a intenção de negar, ou até mesmo de reduzir as experiências de sofrimento das pessoas depressivas. As análises empreendidas aqui ocorrem o tempo inteiro no campo da linguagem, pois muito embora a depressão seja um fenômeno real, vimos que as narrativas psiquiátricas sobre ela não são.

Em segundo lugar, esse artigo também não tem a pretensão de estabelecer uma nova e única verdade acerca da depressão. Quem tem interesse em absolutizar tais questões é a psiquiatria, que com seu DSM, de maneira positivada e neoliberal, tenta nivelar ao igual todas as formas de ser, estar e sofrer das pessoas. Entretanto, as explicações psiquiátricas falaciosas acerca do comportamento depressivo, fazem surgir uma emergência em enxergar a depressão, assim como outras psicopatologias, através de novos olhares. Esse é o objetivo desse texto, e foi o que tentamos fazer ao trazer a filosofia para o centro desse debate por meio das contribuições, sobretudo, de Byung-Chul Han.

Em terceiro lugar, não é propósito desse artigo, esgotar essa discussão. Vemos potencial nesse tema, para diversos desdobramentos futuros, não apenas no campo da filosofia, mas nas ciências humanas de maneira geral. Aliás, isso não somente é recomendado como é emergente. É necessário que os saberes que se debruçam sobre o humano, se apropriem dos fenômenos da existência e usem suas respectivas vozes para oferecer olhares outros para fenômenos como a depressão, por exemplo.

Enxergamos nessa apropriação filosófica, e possivelmente de outros saberes, uma possibilidade interessante de desmedicalizar esses fenômenos característicos da vida humana. Quando a psiquiatria - de forma mentirosa - afirma que a depressão consiste em um desequilíbrio neuroquímico, ela cala o sujeito depressivo, ignora sua história, apaga sua cultura e desresponsabiliza as estruturas sociais, que como foi mostrado nesse texto, possuem um potencial totalmente destrutivo para a psique.

Pensar a depressão para além das explicações biológicas significa, acima de tudo, devolver ao sujeito depressivo, tudo que a psiquiatria tem tomado dele. As análises filosóficas, como as de Han, por exemplo, servem não apenas para desmascarar a perversidade das estruturas sociais sob as quais vivemos, mas servem também para nos lembrar que o sujeito depressivo é, antes de qualquer coisa, um sujeito histórico-cultural, que tem uma voz, que se expressa, que ama, que odeia, que espera, que se frustra e que sofre, e não apenas um corpo cuja biologia/neurologia se encontra disfuncional. 


\section{REFERÊNCIAS BIBLIOGRÁFICAS}

AMARANTE, P.; FREITAS, F. Medicalização em Psiquiatria. Rio de Janeiro: Editora Fiocruz, 2017.

AMERICAN PSYCHIATRIC ASSOCIATION. Manual de Diagnóstico e Estatística de Transtornos Mentais - DSM 5. Porto Alegre: Artmed, 2013.

BAUMAN, Z. Modernidade Líquida. Tradução de Plínio Dentzien. Rio de Janeiro: Zahar, 2001.

Vida Para Consumo: a transformação das pessoas em mercadoria. Tradução de Carlos Alberto Medeiros. Rio de Janeiro: Zahar, 2008.

BULFINCH, T. O Livro de Ouro da Mitologia: histórias de deuses e heróis. Tradução de David Jardim. Rio de Janeiro: Agir, 2014.

FOUCAULT, M. Nascimento da Biopolítica: curso dado no Collège de France (1978-1979). Tradução de Eduardo Brandão. São Paulo: Martin Fontes, 2008.

O Poder Psiquiátrico: curso dado no Collège de France (1973-1974). Tradução de Eduardo Brandão. São Paulo: Martin Fontes, 2006.

HAN, B. C. A Salvação do Belo. Tradução de Gabriel Salvi Philipson. Petrópolis: Editora Vozes, 2019.

. Agonia do Eros. Tradução de Enio Paulo Giachini. Petrópolis: Editora Vozes, 2017a.

. Psicopolítica - o neoliberalismo e as novas técnicas de poder. Tradução de Maurício Liesen. Belo Horizonte: Âyiné, 2018.

2015.

Sociedade do Cansaço. Tradução de Enio Paulo Giachini. Petrópolis: Editora Vozes,

Topologia da Violência. Tradução de Enio Paulo Giachini. Petrópolis: Editora Vozes, $2017 b$.

KLEIN, N. A Doutrina do Choque: a ascensão do capitalismo de desastre. Tradução de Vania Cury. Rio de Janeiro: Nova Fronteira, 2008.

MIOTELlO, V. Bakhtin e o Lugar da Linguagem na Psicologia. São Carlos: Pedro e João Editores, 2018.

ORGANIZAÇÃO PAN-AMERICANA DE SAÚDE. ORGANIZAÇÃO MUNDIAL DA SAÚDE. Folha Informativa - Depressão. Brasília: OPAS/OMS, 2018. Disponível em: $<$ https://www.paho.org/bra/index.php?option=com_content $\&$ view=article\&id=5635:folhainformativa-depressao\&Itemid=1095>. Acesso em: 24 de jul. de 2020.

PONZIO, A. Procurando Uma Palavra Outra. Tradução de Valdemir Miotello, Regina Silva, Daniela M. Mondardo, Camila Caracello Sherma, Marina Haber de Figueiredo, Ana Beatriz e Allan Pugliese. São Carlos: Pedro e João Editores, 2010. 


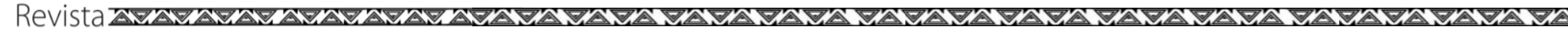 \\ $\triangle P O E N A$

WHITAKER, R. Anatomia de Uma Epidemia: pílulas mágicas, drogas psiquiátricas e o aumento assombroso da doença mental. Tradução de Vera Ribeiro. Rio de Janeiro: Editora Fiocruz, 2017.

Artigo recebido em: 29/07/2020

Artigo aprovado em: 06/09/2020 